\title{
Reading in Biology Classes-A Different Teaching Activity
}

\author{
Simone Paixão Araújo1,2, Maria Helena Silva Carneiro² \\ ${ }^{1}$ Federal Institute of Goiás (IFG), Luziânia, Brazil \\ ${ }^{2}$ University of Brasilia (UnB), Brasília, Brazil \\ Email:simone.paixao@ifg.edu.br,mhsilcar@unb.br
}

Received 23 March 2016; accepted 22 May 2016; published 25 May 2016

Copyright (C) 2016 by authors and Scientific Research Publishing Inc.

This work is licensed under the Creative Commons Attribution International License (CC BY).

http://creativecommons.org/licenses/by/4.0/

(c) ()

\begin{abstract}
It is unthinkable to discuss learning without thinking of the merited prominence of reading and writing, since these are the essential actions for the production of different forms of systematized knowledge, among which is scientific knowledge. From this perspective, the present work proposes answering the following question: to what extent can the proposed pedagogy called reciprocal teaching aid in the development of the abilities of reading and interpretation of scientific texts? The discussion of a text found in a biology textbook was organized around four moments: questioning, summarizing, predicting and clarifying. The analysis of the data shows that the collective work helped in the comprehension of the text and, especially, in the understanding of the meaning of some scientific terms and permitted a deeper and more complex analysis of the text. This would hardly occur in a polarized reading situation in which the professor would present the expected interpretation.
\end{abstract}

\section{Keywords}

Reading, Comprehension, Interpretation, Teaching of Science, Reciprocal Teaching

\section{Reading and Writing in the Teaching of Science}

When the student registers his perceptions and ideas based on a given study material, he can organize his arguments and thoughts regarding the subject. The exercise of writing contributes to make his previous knowledge come to the fore. However to make this knowledge more concrete, the writing exercise directs the student to the revision of his positions and values in order to give them structure. Thus, we consider writing as an important resource and instrument of learning, since it leads the student to the process of authorship. This process requires an underpinning of readings, and life experiences that sustain his production. In our culture, we have orality as 
one of the characteristic marks of our expression in the world and for the world. We converse, we tell stories, we dialogue continuously in our daily activities and often we do not perceive how flexible and fleeting our orally expressed ideas can be. Words flow easily, requiring little attention on the part of our cognitive mechanisms. A different process occurs when we practice writing. To put down our thoughts by means of composition, ordering and argumentation in a written text demands attention, understanding and the establishment of a personal position regarding an idea or reality. This requires arduous and solid cognitive activity. Writing implies bringing out our previous knowledge regarding a given topic, confronting it with a reality and establishing a position that remains registered and evident to our peers. "Oral discourse is divergent, highly flexible and requires little effort of the participants while the explore ideas collectively, but written discourse is convergent, more focused and demands a greater cognitive effort on the part of the writer” (Rivard \& Straw, 2000: p. 583).

A study performed with future science teachers, Nicolli and Cassiani (2012), found that the candidates did not propose reading and writing activities to their students, because they thought that developing such actions would prove difficult or because they held that it did not form part of the objectives of a science teacher, or because they were wary of proposing something that might innovate their routines. A very interesting argument put forward was that reading and writing were secondary processes in the teaching of scientific concepts, the objects of the curriculum. They considered that learning would become concrete when the professor read and wrote transmitting the necessary meanings for the students to learn. That argument does not take into consideration the role of reading in the teaching of science. It contradicts the thinking of Ginsburger-Vogel and Astolfi (1987: p. 33), for whom "skill in reading is a determining factor of academic success". Despite the wide dissemination of the temporary and changing character of scientific knowledge in virtue of advances of learning, we perceive that the future teachers participating in the above-mentioned study continue to hold fast to pedagogical models that treat education as an end in itself, imitating the models and role of knowledge that is finalized and ready to acquire.

Holding on to habits and stereotyped situations regarding the role of teacher and student of science can strengthen the image of science as an absolute truth. We, however, hold that learning goes beyond such thinking. It is a position that limits the possibilities of contributing to the formation of a reflective student capable of entering different contexts with a critical perception of the reality presented. The teacher should orient his action in favor of critical reflection, curiosity and questioning. These characteristics produced in the teacher as well as in his students, by means of reading and writing. It is unthinkable to treat learning without considering the distinction that reading and writing deserve, since they are essential actions for the production of different forms of systematized learning including scientific knowledge. If reading and writing are intrinsic to the production of knowledge, the conditions and importance granted to them define our understanding of science. Reading is so important in the schooling process that many associate the idea of "going to school" with the process of learning to read and write.

Therefore, we ask at what point reading and writing became something mystical, far removed from the activity of the science teacher. We hold that reading and writing are the underpinnings of teaching. Now we have to face yet another myth; some people position themselves passively before the written text, misrepresenting the nature of the reading process. Reading, especially in the classroom, should aim towards a deeper understanding of the context by way of mediation between the written word and life in the concrete, in order to establish the link between daily life and the scientific world.

If we isolate reading and writing from the teaching of science, we worry about the distance hindering the elaboration of the personal discourse of the student that reading promotes. We ask ourselves if the consumption of texts becomes as empty as the consumption of ideas. With such restrictions we eliminate the space reserved for the sharing of experiences, exposition of individual interpretations and the more solid and profitable discussion of ideas. If we do not exercise this relationship between reading, writing and science, will we not be cutting short the development of the students' abilities to read and write? Another challenge we have to face involves the concept that many teachers may have that the literate student before him is necessarily a reader. Being literate is a necessary condition for reading, but it does not necessarily imply the capacity to dialogue with diverse texts that demand different levels of comprehension. One must gradually construct reading abilities so as not to frustrate the student or make him feel incapable of understanding or deepening his criticism of the texts proposed.

Reading is necessary as a basic component of education and the constant search for knowledge. The teacher and the student increase their repertoire of knowledge through the practice of reading understood as an academic obligation since it is part of the equipment needed for the comprehension of reality and intervention in society. 
Although we defend reading as one of the propelling forces for the formation of critical and participative citizens, we recognize that we need to advance in the search and construction of techniques and strategies that permit us to reach these objectives. By means of these strategies systematically applied in the classroom, we wish to break with the dogmatization of ideas linked to texts with the "bank input" vision of textbooks. "The critical teaching of reading should show that books are no more than the expression of thoughts that are subject to errors and susceptible of deepening and questioning” (Silva, 1998: p. 28).

Proceeding from these propositions, we developed a study based on the theoretical proposal of Reciprocal Teaching elaborated by Palincsar and Brown (1984) whose objective was to promote the development of reading comprehension abilities. The authors made it evident; furthermore, that the comprehension of a text was more effective when there was dialogue and orientation in view of a deeper exploration. Teacher and student alternate in the conduction of a text discussion. These discussions are organized around four moments whose order may be modified according to the needs of the group: question, summarize, predict and clarify. The order of these stages varies according to the needs of the students. Thus, the teacher can initially solicit the reading of a portion of the text. Then he may solicit its summary, the prevision of the continuation of the content of the text and finally the clarification of terms and expressions. Alternatively, he may solicit the reading of the complete text and leave the strategy of "summary" to the end. According to the authors, the student who does the summary focuses on the general content of the text and verifies if the group has understood it. The student who proposes questions about the subject also concentrates on the principal ideas of the text and validates its comprehension. When the student is asked to clarify some terms, he makes a critical evaluation during the reading process. Predicting, in turn, permits the questioning of the continuation of the content, make inferences and evaluation during the reading process. These four reading strategies permit the mobilization of previous knowledge. Thus, starting from this proposal, we hope to better the students' capacity to learn from texts. Understanding will grow with the overlapping of previous knowledge to the content of the text in question. Attention can emphasize concentration on the content of the main content. A critical evaluation of the content by means of interpretations, predictions and conclusions allows the student to analyze his capacity of text comprehension.

This study aims to investigate the contribution of the stages of Reciprocal Teaching for the joint construction of the meanings of a read scientific text, in order to promote the abandonment of a passive attitude in the classroom.

\section{The Method of the Study}

The activities were carried out in an institution of the Federal Network of professional, Scientific and Technological Education-IF. The study took place at the Federal Institute of Goiás in Campus Luziânia. These institutes aims to train and qualify professionals for various sectors of the economy. It offers, therefore, from the Integrated Professional Education to High School contemplating Graduation and Post-Graduation. As the planned course to lead the student to the mid-level technical professional qualifications in the same institution, with one registration for each student.

1) Study participants: The campus where we realized the study offers Integrated Technical Courses on Edifications, Computer Science for Internet as well as Integrated Chemistry Courses. We carried out our study using three classrooms, totaling 67 students, who were doing their second year of the Integrated Technical Course on Secondary Education. Because of the extent of the proposal and the multiple possibilities of analysis, we will here present the data regarding one classroom only (Technical Course in Computer Science for Internet), that is, 19 students.

2) Procedures applied for data collection: Considering the fact that the study in question had the objective of verifying to what extent Reciprocal Teaching can help developing abilities of reading and text comprehension of the participating students, we opted to carry out that study in three phases. First, we explained the meaning of the theoretical proposal-Reciprocal Teaching. Secondly, we asked for each student's consent to participate in the activities. Finally, we applied the pedagogical proposal. We organize students into four groups of four students and one group of three students, which makes five groups. Then we distributed the text entitled "Edible Vaccines" so that the students could begin the tasks. The first stage of Reciprocal Teaching, Prediction, consisted in constructing hypotheses about the content of the text. For this, the students used textual clues such as title, subtitles and images. During the second stage, individual reading of the text, the students identified the terms and expressions with which they were not familiar. In the following moment, including the stages of Clarifying and Questioning, the students expressed their doubts to the group for clarification and/or consulting other imme- 
diately available sources. Finally, came the moment of Summary, based on the group's discussion they did a written summary of the ideas elaborated by the group.

We emphasize that during the development of activities under the Education Reciprocal made throughout the process formative assessment, which aimed at the regulation of student learning in an educational proposal. We understand that in teaching situations stimulating and adjustments that occur favor adjusting the action and representations of students, in addition to the student to identify their mistakes. According Perrenoud (1999), in teaching proposal students can learn by trial and error, cognitive conflicts and intellectual cooperation. Formative assessment gives teachers information to intervene and regulate in student learning. We audio recorded all the meetings for later analysis of the activities.

\section{Analysis of the Data}

After initial explanations of the planned procedures, the first activity consisted in raising hypotheses regarding the content of the text based on title, subtitles and accompanying images. The title of the text was "Edible Vaccines" (see the highlighted image below). The students spent from three to five minutes in this activity called Predicting.

Upon seeing the image (Figure 1), the students raised hypotheses that the text referred to a new form of vaccination and some of them supposed that "eating a potato containing the bacterial cell you are immunized". Some even imagined that edible vaccines "are medicinal plants". Despite the fact that the image presented a series of indications regarding the different stages of the process, the students did not manage to conclude that genes of the bacteria are transfered from a cell of the plant, making it genetically modified. Such observations lead us to confirm the idea that the reading of images is an important process, which the teacher must mediate. According to Pereira (2013: p. 107) "an image, of itself, does not teach; the instructor must help the student and teach him to look closely at the image in order to perceive a wider network of meanings and information”. We also found affirmations such as "it is a flowchart" and "it has a tutorial of how to produce a vaccine, so it must be quite good". Such student observations show that at that stage they try to apply, in a different context, a specific language of their own area of formation. In their daily life, the students of Computer Science for Internet must use flowcharts and the must often seek solutions for their problems through tutorials found in websites. The dialogues between students show that they create representations of the images present in texts, that is, they reinterpret the exterior image based on their former knowledge.

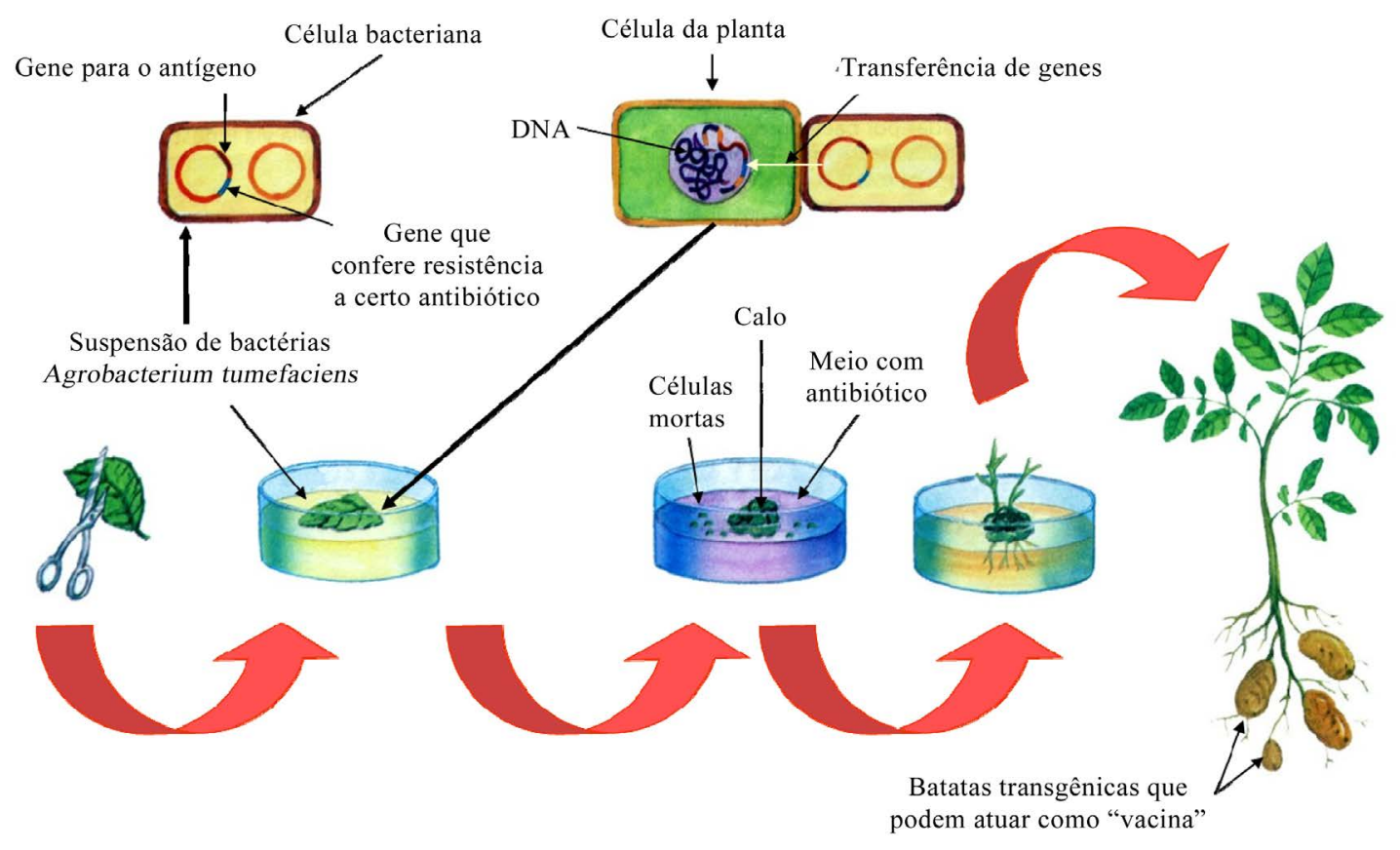

Figure 1. Representation of the edible vaccine this production process used in the text (Lopes, 2006). 
Next, the students did an initial reading and identified terms and expressions with which they were not familiar. The students highlighted the following words: antigens, pathogens, lymphocytes, macrophages, cytotoxic, transgenic and capsid. This activity pertained to the stage called Clarifying. The meaning of antigen was present in the text and some students found it and helped those colleagues who had not found the explanation. We remind you that each group had access to a Portuguese dictionary, though we recognize that, depending on the type of dictionary, some words are not present. In that case, the role of the teacher and the collective work of the group are indispensable to help make out the meaning of such words. The students' lack of familiarity with such terms shows a lack of grasp of concepts relating to cytology, a subject they had studied the previous year.

Later on in each group, the students individually elaborated an oral report in which they presented their understanding regarding the text each had read. We point out that, in the oral summary, besides expressing the comprehension of the text, the students presented some questioning regarding the subject and probable implications of the process of production and distribution of edible vaccines. This questioning appeared in the text that the students wrote on the effectiveness of that new form of immunization. "If they will bring the same or better results as vaccines already known. If the modification of genes in food can bring harm to nature (Group 3)”. Of the four texts produced by the students, at least three (1, 3 and 4) pointed out the social dimension of the new vaccine being studied, that is, the accessibility of the vaccine for geographically isolated persons or for populations in precarious life conditions, without access to electric energy. The dialogue that occurred in each group shows a critical examination of the text. By way of example, we point out that the students argued regarding the necessity of doing tests to prove the efficacy of the vaccine and the production of antibodies, the definition of the amount of treated food the individual would have to eat and the frequency of ingestion. We emphasize that there was some questioning regarding possible allergic food reactions in some persons and the restriction of some foods, as in the case of diabetics. These considerations could make these foods not viable for such persons. We consider such questioning relevant and indicative of a critical vision in the acquisition of facts and their possible implications. This validates the observations of the authors of the proposal who affirm that "as time passed, the questions of the students became more like those of the teacher, being classified as creations, that is, questions and summaries essentially in their own words, rather than repetitive selections of words found in the text” (Palincsar \& Brown, 1984: p. 135). Besides that, we point out that a teacher's presentation on the subject could not evoke such complex and profound approaches.

The text we used points out some well-established and successful preliminary tests, but does not clarify which factors might raise difficulties for the process, aside from the fact that the images present complex and specific information regarding the production of the vaccines and their trajectory within the human body. We confirmed the necessity of constructing meanings through the questioning of the students with regard to the lack of details and specificities not presented in the text, but which appear in the images and without due identification.

The analysis of the dialogue of the students while creating the oral summaries made it possible to identify the presence of certain erroneous concepts among them regarding the distinction between vaccine and serum. A female student presented the process of serum production through injection of a toxin into horses and compared it to injecting it into a potato. She explained to her colleague that the potato would produce the antibodies and the "vaccine" would not last long and that people would have to ingest this "vaccine" every week because the antibodies were not long lasting. We perceived in this fault an erroneous construct associating attributes of the concept of serum to the concept of vaccine. We also found an interpretation such that the "vaccine" is "injected" into the plant. This makes it evident that the concept of a transgenic organism is still confused and not assimilated according to its scientific concept. Another student reported the case of diabetics who are "vaccinated" daily with insulin. This clearly shows the lack of comprehension regarding the hormone administered to diabetics and its therapeutic nature. Such stories make it evident that the use of scientific words and terms does not mean that the person using them understands their meaning. Therefore, reading in the science classroom with the mediation of the teacher is an important strategy for the presentation of concepts. It makes possible the construction of specific meanings and permits the broadening of understanding of scientific terms.

\section{Final Considerations}

One of the strong points of reciprocal teaching is the interlocution among the students. That exchange permits the confrontation of ideas, their evaluation and, when necessary, their restructuring. This further propitiates the development of the autonomy of the student. When we ask the student to foresee the content of the text before 
diving into its reading, the student learns that elaborating a hypothesis is not like building in the void. He makes use of concrete clues such as title, subtitle, image and his own previous knowledge. This aspect remained evident in the text of Group 2, when it describes the activity preceding the elaboration of the summary. Clarifying unfamiliar terms and expressions permitted the student to verify that he is not the only one who does not recognize the meaning of certain words. Questioning demands a more attentive reading, permitting progress in the comprehension of the text. The analysis of the questions proposed by the students allows us to confirm the presence of a critical vision with respect to the subject. Finally, summarizing was another stage that made for ample discussion in the group, since its production demanded long negotiation among the participants. The idea of asking for an oral summary, before the written text, facilitated negotiation among the students during the elaboration of the written summary.

In this type of activity, the students are the active protagonists. Based on their own ideas they gradually construct their understanding of the text. The teacher plays the role of animator. He guides the activity to the extent that he calls attention to certain passages that may have gone unnoticed and he helps the students to establish new relationships. It is worth noting that in certain moments the student who better dominates the reading can assume the role of the teacher.

We consider the present study an important indicator of the need of a better investigation of how students interpret the images presented in the different texts used in the classroom. It is likewise vital to evaluate the production of meanings established based on the reading of scientific texts. Giving the student the responsibility of analyzing and presenting his ideas based on his reading changes the priority of conducting activity in the classroom. The focus ceases to be the objective that the teacher presumes to achieve and shifts to the student who becomes autonomous to interpret the data, distancing reading from the predictability expected by the teacher.

This study shows that the autonomy of the students to interpret texts can lead to other more solid and more profitable reading. Furthermore, it is a practice of promotion of critical teaching of science and technology in a concrete form in the context of the classroom. Meanwhile, an analysis of the interpretations elaborated by the students regarding the text shows mistaken explanations of scientific concepts. One would not easily perceive this in a polarized reading situation in which the teacher would present the expected interpretation, for him, as if the meaning of the text were fixed and unique. Corroborating the study of Andrade and Martins (2006) regarding the analysis of the discourse of the teachers of science regarding reading they found that

Even if the teacher values critical reading, the broadening of worldview, the role of the everyday in the attribution of meaning to scientific terms, etc., there predominates, in his own readings as well as in the activities of proposed readings in the classroom a way of reading that seeks the implication of the author in its regard (Andrade \& Martins, 2006: p. 147).

After carry out this initial study, we observed that the reading other scientific genre texts, the students showed progress in reading and comprehension of the text. Although this progress has not been very significant, we observed that the students were located more easily the information needed to solve the exercises and not feel inhibited to request the explanation of an unfamiliar term.

Our analysis shows the necessity of more solid studies regarding the interpretation of texts and images in the classroom in the process of the elaboration of scientific terms. Besides, they would allow us to comprehend better the manner in which students interpret and analyze didactic texts that bring scientific information when they have the possibility of expressing their own reading of the material presented in the text. The way the students analyzed and organized scientific concepts, shows us how revealing and fruitful could be a denser investigation of the process of collaboration among students in the elaboration of meaning gathered from a reading experience in science classes.

\section{Acknowledgements}

We thank the Federal Institute of Goiás-IFG the resources available for the development of the study and publication of the article.

\section{References}

Andrade, I. B., \& Martins, I. (2006). Science Teacher’s Discourse about Reading. Investigações em Ensino de Ciências, 11, 121-155. 
Ginsburger-Vogel, Y., \& Astolfi, J.-P. (1987). Sur la lecture des manuels de Biologie. ASTER, 4, 33-56. http://dx.doi.org/10.4267/2042/9176

Lopes, S. G. B. C. (2006). Bio: Volume 2. São Paulo: Saraiva.

Nicolli, A., \& Cassiani, S. (2012). Stories of Reading and Writing to Educational Practice Reading and Writing Future Science Teachers. Alexandria, 5, 69-81.

Palincsar, A. S., \& Brown, A. L. (1984). Reciprocal Teaching of Comprehension-Fostering and Comprehension-Monitoring Activities. Cognition and Instruction, 1, 117-175. http://dx.doi.org/10.1207/s1532690xci0102_1

Pereira, S. P. A. (2013). Entomology Teaching Proposal in High School in Youth Education Modality and Adults with Use of Audiovisual Resources. Master Dissertation, Brasília: Brasília University.

Perrenoud, P. (1999). Rating: Excellence to the Regulation of Learning between Two Logics. Porto Alegre: Artmed.

Rivard, L. P., \& Straw, S. B. (2000). The Effect of Talk and Writing on Learning Science: An Exploratory Study. Science Education, 84, 566-593. http://dx.doi.org/10.1002/1098-237X(200009)84:5<566::AID-SCE2>3.0.CO;2-U

Silva, E. T. (1998). Reading Pedagogy Elements (3rd ed.). São Paulo: Martins Fontes. 